\title{
Frontotemporal dementia and Alzheimer's disease: retrospective differentiation using information from informants
}

\author{
R Barber, J S Snowden, D Craufurd
}

\begin{abstract}
The study examined the feasibility of differentiating frontotemporal dementia from Alzheimer's disease on the basis of retrospective historical information obtained from relatives of patients. A structured questionnaire was devised of patients' symptoms, with emphasis on those cognitive and neuropsychiatric features found in earlier prospective clinical studies to distinguish the two conditions. The questionnaire was given to close relatives of deceased patients in whom the diagnosis of non-Alzheimer's frontotemporal degeneration or Alzheimer's disease had been verified at necropsy. The interviewer had no previous contact or knowledge of those patients, nor clinical experience of patients with frontotemporal dementia. The questionnaire elicited a distinct profile of responses for the two diagnostic groups with emphasis on early personality change, unconcern, and socially inappropriate behaviour in frontotemporal dementia and disturbance in memory and topographical orientation prominent in patients with Alzheimer's disease. A scoring system separated out individual patients with frontotemporal dementia from those with Alzheimer's disease. It is concluded that it is possible to obtain useful information about the precise pattern of dementia from informants even many years after the patient's death. The questionnaire provides the foundation of a diagnostic instrument for use in family history studies of dementia.
\end{abstract}

$(F$ Neurol Neurosurg Psychiatry 1995;59:61-70)

Keywords: frontotemporal dementia; Alzheimer's disease; retrospective differentiation

Departments of Psychiatry and Neurology,

Manchester Royal Infirmary and Department of Medical Genetics, St Mary's Hospital, Manchester, UK R Barber

J S Snowden

D Craufurd

Correspondence to:

Dr J S Snowden, Cerebral Function Unit, Department of Neurology, Manchester Royal Infirmary, Mancheste M13 9WL, UK.

Received 25 November 1994 and in revised form 14 February 1995

Accepted 15 February 1995 sis..$^{5-7}$ In a few cases only inflated neurons and Pick bodies are present, conforming to pathological criteria for Pick's disease. There are no clinical differences to distinguish patients with frontal lobe degeneration type ${ }^{7}$ and Pick type pathology. The condition may affect up to $25 \%$ of patients with primary degenerative dementia in the presenium. ${ }^{128}$

Frontotemporal dementia seems strongly familial: a positive family history of dementia has been reported in up to $50 \%$ of cases, ${ }^{128}$ suggesting the importance of genetic factors in the aetiology. No systematic family study of this disorder has, however, been carried out to date. There are methodological difficulties inherent in family studies of dementia, and in frontotemporal dementia in particular. On the one hand, the age at onset is relatively late, so that parents of affected people will seldom be available for examination, and may have died of other causes before onset of symptoms of dementia, so that some familial cases may be overlooked. On the other hand, in family studies of frontotemporal dementia positively identified cases may have had the more common form of dementia, Alzheimer's disease. Most family studies of dementia have used very broad diagnostic criteria. Some attempt may be made to distinguish vascular from primary degenerative dementias on the basis of historical features and physical signs, but rarely will studies attempt to distinguish between forms of primary degenerative dementia. Yet such differentiating information is vital in studies of frontotemporal dementia if the prevalence of a positive family history and mode of inheritance is to be accurately determined.

There is good evidence that frontotemporal dementia can be distinguished effectively from Alzheimer's disease on clinical grounds. ${ }^{1289}$ Clinical evaluation characteristically includes neurological and neuropsychological assessment and brain imaging of the patient in addition to a clinical history obtained from patients' relatives. It is not clear whether an accurate diagnosis could be made on the basis of historical information alone, and in particular from information obtained retrospectively with respect to a deceased patient. The purpose of this study was to establish the feasibility of using informant information to distinguish retrospectively between frontotemporal dementia and Alzheimer's disease and to identify those most discriminating historical features for use in the development of a questionnaire to be used in family studies of frontotemporal dementia. 


\section{Methods}

DEVELOPMENT OF AN INFORMANT BASED QUESTIONNAIRE

A questionnaire was developed consisting of two parts (see Appendix). The first part was designed to screen for the presence of dementia. Questions were broad, and covered the range of symptoms found in most diagnostic classifications of dementias such as DSM-IIIR, ${ }^{11}$ ICD-10,12 and NINCDS-ADRDA. ${ }^{13}$ The second part was designed to distinguish between frontotemporal dementia and Alzheimer's disease. Questions covered those cognitive, behavioural, and physical changes found to differentiate the dementias in longitudinal studies. ${ }^{12814-16}$ In addition, questions were included relating to neuropsychiatric symptoms, an important feature of degenerative dementias, ${ }^{1718}$ although currently little is known about the relative differential importance of these changes. These questions were adapted from Burns et al. ${ }^{19-21}$ The questionnaire design also permitted collection of information about the stage in the illness at which a symptom first appeared, as this might discriminate better than the presence or absence of the symptom itself. Questions were included to establish the total duration of illness, which was divided into thirds, referred to as early, middle and late stages. For each positive symptom it was determined at which of the three stages it first appeared.

\section{PATIENTS}

Patients were drawn from a population of 55 patients with necropsy confirmation of frontotemporal degeneration $(n=21)$ or Alzheimer's disease $(n=34)$, most of whom had been studied during life in the department of neurology, Manchester Royal Infirmary.

Pathological findings in patients with frontotemporal dementia have been described elsewhere. $^{622}$ Briefly, brains were characterised by frontal and temporal atrophy, with severe neuronal loss, and varying prominence of spongiosus and gliosis. Neurofibrillary tangles and neuritic plaques were absent. Conversely, brains from patients with Alzheimer's disease showed numerous neurofibrillary tangles and neuritic plaques.

Interview data were obtained for a group of 12 men and six women with frontotemporal dementia, and six men and 14 women with Alzheimer's disease. The median age of onset of illness was 55 (range 44-64) years for patients with frontotemporal dementia and 59 (range 38-76) years for patients with Alzheimer's disease. The duration of illness was significantly longer in the Alzheimer's disease group (median 6.5 years for frontotemporal dementia and nine years for Alzheimer's disease, $\mathbf{P}<0.05)$. There was no difference in socioeconomic status between the two groups.

\section{INFORMANTS AND PROCEDURE}

The next of kin of deceased patients, as recorded in the hospital case notes, were consulted to identify the most knowledgeable informant willing to be interviewed for the study. Informants for 38 of the original 55 patients (18 with frontotemporal dementia and 20 with Alzheimer's disease) were finally interviewed. Of the other 17 patients, informants for two patients with frontotemporal dementia and three with Alzheimer's disease declined to be interviewed, and those for one patient with frontotemporal dementia and 11 with Alzheimer's disease could not be traced. Data for one patient with Alzheimer's disease were excluded from analysis because comorbidity caused premature death, restricting symptomatic expression of the dementia to the early stage. Thus analyses were based on data for 18 patients with frontotemporal dementia and 19 with Alzheimer's disease.

Where possible a second independent interview was conducted with another family member or members. Seven patients with frontotemporal dementia and eight with Alzheimer's disease were given secondary interviews. Interviews, whether primary or secondary, usually involved a single informant but occasionally a consensus of more than one opinion.

The median time between onset of dementia and interview was 9.2 years for the frontotemporal dementia group and 13.3 years for the Alzheimer's disease group, and between death and interview it was two years for patients with frontotemporal dementia and three years for patients with Alzheimer's disease. The interviewer, who had no previous contact with either patients or their relatives, was blind to diagnosis. Interviews were conducted face to face, with the exception of one which was conducted by telephone. Interviews took an average of 100 minutes to complete.

\section{ANALYSIS OF RESULTS}

$\chi^{2}$ or Fisher's exact tests were carried out to measure the discriminating value of individual questionnaire items. Data were also subjected to logistic regression analyses. Response profiles were examined blind by one author and categorised as frontotemporal dementia or Alzheimer's disease on the basis of the overall pattern of responses.

The data obtained from the questionnaire provided the basis for development of a scoring system, the purpose of which was to yield an overall summary score that would most accurately assign patients to one or other of the two diagnostic groups.

\section{Results}

As expected the screening questions in part I of the interview identified the presence of dementia in every subject and each symptom was reported almost invariably for patients in both groups. The two groups differed with respect to the first reported symptom $(\mathrm{P}<$ $0 \cdot 001)$. Personality changes were identified as the first symptom in $68 \%$ of patients with frontotemporal dementia, whereas memory impairment occurred first in $74 \%$ of patients with Alzheimer's disease. For almost all the patients the onset and progression of dementia was described as gradual $(96 \%)$. 
Forty two of the original 87 questions elicited differences between frontotemporal dementia and Alzheimer's disease (table 1) and in general questions became more discriminating if related to the period during the course of disease in which the symptom first appeared (early, middle, or late phase). As predicted, in general, personality changes were reported more often in frontotemporal dementia and cognitive changes more often in Alzheimer's disease.

Some memory changes were reported with respect to both groups, certain questions eliciting a $100 \%$ positive response rate; however, early symptoms of memory failure were reported significantly more often for Alzheimer's disease. There were two aspects of memory performance that distinguished the groups regardless of phase of illness. Patients with Alzheimer's disease were all reported to lose objects whereas in patients with frontotemporal dementia this was rare. Patients with Alzheimer's disease who wandered would tend to get lost, whereas those with frontotemporal dementia would wander without getting lost. Reports of disorientation in time and place occurred with respect to both groups. Early disorientation occurred more commonly with respect to Alzheimer's disease and absence of disorientation during the illness occurred only in frontotemporal dementia.

With regard to language performance, paraphasias and the use of "wrong words" occurred significantly more often in Alzheimer's disease than in frontotemporal dementia, whereas mutism was more common in frontotemporal dementia, occurring even in the middle phase of disease. Spatial, topographical symptoms strongly favoured Alzheimer's disease. All patients with Alzheimer's disease had some symptoms during their illness, would get lost in both familiar and unfamiliar surroundings, and had dressing and face recognition problems, and all but one patient were reported to get lost in the home and have difficulty locating objects in front of them. The absence of such symptoms during the course of the illness favoured a diagnosis of frontotemporal dementia.

"Personality" changes were always reported as an early symptom in frontotemporal dementia, whereas in Alzheimer's disease the time of onset of personality changes varied. Loss of empathy, inappropriateness of affect, and behavioural disinhibition strongly favoured a diagnosis of frontotemporal dementia. They occurred in the early and middle phases of frontotemporal dementia, and for the most part not at all in Alzheimer's disease. Conversely, reports of aggression were more common in Alzheimer's disease. A desire for sweet foods and a tendency to hide objects were reported in only a few cases; the presence of the first favoured frontotemporal dementia whereas the second favoured Alzheimer's disease.

Abnormal beliefs and misperceptions were reported relatively rarely, and occurred almost exclusively in association with Alzheimer's disease. Patients were reported to show suspiciousness of others, to believe that belongings had been stolen, to misidentify others and themselves in a mirror, and to misconstrue events or persons on the television as taking place or being present in the room. Visual hallucinations were reported occasionally in Alzheimer's disease, but never in frontotemporal dementia.

Mood changes were strong discriminators between the groups. Patients with Alzheimer's disease commonly showed anxiety and distress in the face of handicaps and loss of confidence, manifest in the early stages of the illness. Patients with frontotemporal dementia were rarely reported to show such concern and in no case was there a perceived loss of confidence. Similarly, physical signs of myoclonus and epilepsy strongly favoured a diagnosis of Alzheimer's disease rather than frontotemporal dementia.

\section{LOGISTIC REGRESSION ANALYSIS}

Losing objects was the single most discriminating symptom and characteristic of Alzheimer's disease. With step forward logistic regression this question predicted the correct diagnosis in $95 \%$ of subjects when the time of symptom onset was considered, reducing to $86 \%$ in the present or absent format. In this particular sample no other variable added extra significant discrimination.

\section{SECONDARY INTERVIEWS}

Data obtained from a second interview were available for seven of the 18 patients with frontotemporal dementia and eight of the 19 patients with Alzheimer's disease. As before, the initial screening questions correctly identified the presence of a dementia syndrome in every case. The percentage agreement between the primary and secondary interviews for the significant questions was calculated. The mean overall between-informant reliability was $84 \%$ for questions in the present or absent format, and $63 \%$ when the stage on onset was considered.

\section{CLASSIFICATION OF FRONTOTEMPORAL}

DEMENTIA V ALZHEIMER'S DISEASE

Questionnaire responses from all 37 primary and 15 secondary interviews were each transcribed on to a score sheet, which was assigned an anonymous number code and given in randomised order to one of the authors (JS), who had played no part in data collection. She was asked to classify each case as frontotemporal dementia or Alzheimer's disease on the basis of the overall profile of responses. Patients were classified with $100 \%$ accuracy.

\section{SCORING SYSTEM}

For the purpose of producing an overall score only those questionnaire items that yielded a significant group difference at $\mathrm{P}<0.001$ were used (table 1). Symptom responses favouring a diagnosis of frontotemporal dementia were scored positively and those favouring a 
Table 1 Summary of discriminating questions

\begin{tabular}{|c|c|c|c|c|c|c|c|}
\hline \multirow[b]{2}{*}{ Questions } & $\begin{array}{l}\text { No of respo } \\
\text { diagnosis a }\end{array}$ & $\begin{array}{l}\text { es per qu } \\
\text { stage at }\end{array}$ & $\begin{array}{l}n \text { by } \\
\text { tt }\end{array}$ & & & $\begin{array}{l}\text { Presence- } \\
\text { absence }\end{array}$ & $\begin{array}{l}\text { Early-middle- } \\
\text { late }\end{array}$ \\
\hline & Diagnosis & Early & Middle & Late & Absent & Significance & Significance \\
\hline Memory:† & & & & & & & \\
\hline Any impairment of & FTD & 6 & 7 & 5 & 0 & NS & $\star \star \star$ \\
\hline memory & $\mathrm{AD}$ & 18 & 1 & 0 & 0 & & \\
\hline Recent memory loss & FTD & 6 & 7 & 4 & 0 & NS & $\star \star \star$ \\
\hline & $\mathrm{AD}$ & 18 & 1 & 0 & 0 & & \\
\hline New learning & FTD & 6 & 8 & 4 & 0 & NS & $\star \star \star$ \\
\hline difficulties & $\mathrm{AD}$ & 18 & 1 & 0 & 0 & & \\
\hline Regularly loses objects & FTD & 0 & 2 & 2 & 14 & $\star \star \star$ & $\star \star \star$ \\
\hline & $\mathrm{AD}$ & 18 & 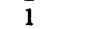 & 0 & 0 & & \\
\hline Remote memory & FTD & 1 & 9 & 5 & 2 & NS & $\star$ \\
\hline loss & $\mathrm{AD}$ & 9 & 9 & 1 & 0 & & \\
\hline Talks about the past & FTD & 2 & 2 & 0 & 14 & * & $\star$ \\
\hline If wanders, usually gets & $\begin{array}{l}\text { AD } \\
\text { FTD }\end{array}$ & 7 & $\mathrm{Yes}^{6}=0$ & $\begin{array}{l}0 \\
0=10\end{array}$ & 6 & & \\
\hline lost & $\mathrm{AD}$ & & Yes $=1$ & Jo $=1$ & & (Fisher's exact) & Not asked \\
\hline Disorientation: time & FTD & 1 & 8 & 5 & 4 & NS & $\star \star$ \\
\hline & $\mathrm{AD}$ & 6 & 12 & 1 & 0 & & \\
\hline Disorientation: place & FTD & 1 & 5 & 6 & 6 & $\star$ & $\star \star \star$ \\
\hline Tomengen & $\mathrm{AD}$ & 11 & 7 & 1 & 0 & & \\
\hline Language: & & & & & & & \\
\hline Verbal stereotypies & FTD & 7 & 1 & 1 & 9 & NS & $\star$ \\
\hline & $\mathrm{AD}$ & 0 & 5 & 2 & 12 & & \\
\hline Paraphasiae: incoherency & FTD & 0 & 2 & 0 & 16 & $\star \star \star$ & $\star \star \star$ \\
\hline & $\mathrm{AD}$ & 8 & 6 & 4 & 1 & & \\
\hline Lose track of speech & $\begin{array}{l}\text { FTD } \\
\text { AD }\end{array}$ & $\begin{array}{l}4 \\
9\end{array}$ & $\begin{array}{l}5 \\
2\end{array}$ & $\begin{array}{l}0 \\
3\end{array}$ & $\begin{array}{l}9 \\
5\end{array}$ & NS & $\star$ \\
\hline Less spontaneous & FTD & 7 & 11 & $\begin{array}{l}3 \\
0\end{array}$ & 0 & NS & $\star$ \\
\hline conversation & $\mathrm{AD}$ & 7 & 7 & 5 & 0 & & \\
\hline Mutism & FTD & 0 & 6 & 8 & 4 & $\star \star \star$ & $\star \star \star$ \\
\hline & $\mathrm{AD}$ & 0 & 0 & 3 & 16 & & \\
\hline Topography: & & & & & & & \\
\hline Any impairment & FTD & 0 & 8 & 9 & 1 & NS & $\star \star \star \star$ \\
\hline & $\mathrm{AD}$ & 14 & 5 & 0 & 0 & & \\
\hline Navigational difficulties & FTD & 3 & 5 & 6 & 3 & NS & $\star \star \star$ \\
\hline in new environments & $\mathrm{AD}$ & 13 & 6 & 0 & 0 & & \\
\hline Navigational difficulties & FTD & 0 & 4 & 6 & 8 & $\star \star \star$ & $\star \star \star$ \\
\hline $\begin{array}{l}\text { in neighbourhood } \\
\text { Navigational difficulties }\end{array}$ & $\begin{array}{l}\mathrm{AD} \\
\text { FTD }\end{array}$ & $\begin{array}{l}9 \\
0\end{array}$ & $\begin{array}{l}9 \\
0\end{array}$ & $\begin{array}{l}1 \\
6\end{array}$ & $\begin{array}{r}0 \\
12\end{array}$ & $\star \star \star$ & $\star \star \star$ \\
\hline in home & $\mathrm{AD}$ & 0 & 15 & 3 & 1 & & \\
\hline Impaired facial & FTD & 0 & 3 & 8 & 7 & $\star$ & $\star \star \star$ \\
\hline recognition & $\mathrm{AD}$ & 3 & 11 & 5 & 0 & & \\
\hline Impaired object & FTD & 0 & 2 & 3 & 12 & $\star \star \star$ & $\star \star \star \star$ \\
\hline recognition & $\mathrm{AD}$ & 2 & 10 & 3 & 2 & & \\
\hline Impaired object & FTD & 0 & 1 & 5 & 12 & $\star \star \star$ & $\star \star \star$ \\
\hline location & $\mathrm{AD}$ & 3 & 8 & 4 & 1 & & \\
\hline Dressing & FTD & 1 & 6 & 8 & 3 & NS & $\star \star \star$ \\
\hline difficulties & $\mathrm{AD}$ & 8 & 10 & 1 & 0 & & \\
\hline Impaired object & FTD & 0 & 3 & 11 & 4 & NS & $\star \star \star \star$ \\
\hline manipulation & $\mathrm{AD}$ & 8 & 9 & 2 & 0 & & \\
\hline Personality change: & & & & & & & \\
\hline Any change in & FTD & 18 & 0 & 0 & 0 & NS & $\star \star \star$ \\
\hline personality & $\mathrm{AD}$ & 8 & 9 & 1 & 1 & & \\
\hline Loss of empathy & FTD & 12 & 1 & 1 & 4 & $\star \star \star$ & $\star \star \star$ \\
\hline & $\mathrm{AD}$ & 2 & 0 & 1 & 16 & & \\
\hline Inappropriate affect & FTD & 6 & 5 & 0 & 7 & $\star \star \star$ & $\star \star \star \star$ \\
\hline & $\mathrm{AD}$ & 0 & 1 & 0 & 18 & & \\
\hline Disinhibition & FTD & 9 & 4 & 0 & 5 & $\star \star \star$ & $\star \star \star \star$ \\
\hline & $\mathrm{AD}$ & 0 & 2 & 0 & 17 & & \\
\hline Increased aggression & FTD & 3 & 1 & 1 & 13 & $\star \star \star$ & $\star \star \star \star$ \\
\hline & $\mathrm{AD}$ & 1 & 8 & 5 & 5 & & \\
\hline Desire for sweet foods & FTD & 3 & 5 & 2 & 8 & $\star$ & $\star$ \\
\hline & $\mathrm{AD}$ & 1 & 0 & 2 & 16 & & \\
\hline Hiding behaviours & FTD & 0 & 1 & 0 & 17 & $\star$ & $\star$ \\
\hline & $\mathrm{AD}$ & 6 & 2 & 0 & 11 & & \\
\hline $\begin{array}{l}\text { Abnormal beliefs and } \\
\text { perceptions: }\end{array}$ & & & & & & & \\
\hline Suspicion & FTD & 3 & 1 & 0 & 14 & $\star \star \star$ & $\star \star \star$ \\
\hline & $\mathrm{AD}$ & 7 & 6 & 3 & $\begin{array}{r}14 \\
3\end{array}$ & & \\
\hline Delusions of theft & FTD & 1 & 0 & 0 & 17 & $\star \star \star$ & $\star$ \\
\hline & $\mathrm{AD}$ & 5 & 3 & 1 & 10 & & \\
\hline Misidentify others & FTD & 1 & 1 & 0 & 16 & * & NS \\
\hline & $\mathrm{AD}$ & 3 & 5 & 1 & 10 & & \\
\hline Misidentify self & FTD & 0 & 0 & 1 & 14 & * & NS \\
\hline & $\mathrm{AD}$ & 1 & 4 & 2 & 9 & & \\
\hline Misidentify television & FTD & 0 & 0 & 0 & 18 & * & NS \\
\hline & $\mathrm{AD}$ & 1 & 3 & 1 & 13 & & \\
\hline Hallucinations & FTD & 0 & 0 & 0 & 18 & $\star \star$ & $\star$ \\
\hline & $\mathrm{AD}$ & 2 & 1 & 1 & 12 & & \\
\hline Mood changed & & & & & & & \\
\hline Distress in response to & FTD & 0 & 0 & 0 & 18 & $\star \star \star$ & $\star \star \star \star$ \\
\hline handicaps & $\mathrm{AD}$ & 10 & 4 & 1 & 4 & & \\
\hline Anxiety in response to & FTD & 1 & 0 & 1 & 16 & $\star \star \star$ & $\star \star \star$ \\
\hline 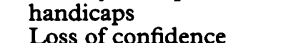 & $\begin{array}{l}\text { AD } \\
\text { FTD }\end{array}$ & $\begin{array}{l}9 \\
0\end{array}$ & $\begin{array}{l}5 \\
0\end{array}$ & $\begin{array}{l}0 \\
0\end{array}$ & $\begin{array}{r}5 \\
18\end{array}$ & $\star \star \star$ & $\star \star \star$ \\
\hline Loss of confidence & AD & 8 & 1 & 0 & $\begin{array}{l}10 \\
10\end{array}$ & & \\
\hline Irritability & FTD & 2 & 2 & 1 & 13 & NS & $\star$ \\
\hline & $\mathrm{AD}$ & 6 & 4 & 2 & 7 & & \\
\hline Physical & & & & & & & \\
\hline Myoclonus & FTD & $\begin{array}{l}0 \\
3\end{array}$ & $\begin{array}{l}0 \\
4\end{array}$ & $\begin{array}{l}1 \\
3\end{array}$ & $\begin{array}{r}17 \\
8\end{array}$ & $\star \star \star$ & $\star \star \star$ \\
\hline Epilepsy & FTD & 0 & 0 & & 18 & $\star \star$ & $\star \star$ \\
\hline & $\mathrm{AD}$ & 0 & 1 & 6 & 12 & & \\
\hline
\end{tabular}

${ }^{\star} \mathrm{P}<0.05 ;{ }^{\star \star} \mathrm{P}<0.01 ;{ }^{\star \star \star} \mathrm{P}<0.01, \chi^{2}$ test.

$\mathrm{n}=18$ for frontotemporal dementia (FTD) group; $\mathrm{n}=19$ for Alzheimer's disease (AD) group. †Excludes "don't know" replies. 
Table 2 Method for scoring questionnaire

\begin{tabular}{|c|c|c|c|c|}
\hline Questions & $\begin{array}{l}\text { Onset in } \\
\text { early stage }\end{array}$ & $\begin{array}{l}\text { Onset in } \\
\text { middle stage }\end{array}$ & $\begin{array}{l}\text { Onset in } \\
\text { late stage }\end{array}$ & Absent \\
\hline \multicolumn{5}{|l|}{ Memory } \\
\hline Any memory impairment & -1 & & & \\
\hline Recent memory loss & -1 & & & \\
\hline New learning difficulties & -1 & & & \\
\hline Regularly loses objects & -1 & & & +1 \\
\hline Disorientation-place & -1 & & & \\
\hline \multicolumn{5}{|l|}{ Language } \\
\hline Paraphasiae & -1 & & & +1 \\
\hline Mutism & +1 & & & -1 \\
\hline $\begin{array}{l}\text { Topography } \\
\text { Any impairment }\end{array}$ & -1 & & & \\
\hline $\begin{array}{l}\text { Navigation difficulties } \\
\text { in new environments }\end{array}$ & -1 & & & \\
\hline $\begin{array}{l}\text { Navigational difficulties } \\
\text { in neighbourhood }\end{array}$ & -1 & & & +1 \\
\hline $\begin{array}{l}\text { Navigational difficulties } \\
\text { within home }\end{array}$ & & -1 & & +1 \\
\hline Impaired facial recognition & & -1 & & \\
\hline Impaired object recognition & & -1 & & +1 \\
\hline Impaired object location & & -1 & & +1 \\
\hline Dressing problems & -1 & & & \\
\hline Impaired object manipulation & -1 & & & \\
\hline \multicolumn{5}{|l|}{$\begin{array}{l}\text { Personality } \\
\text { changes }\end{array}$} \\
\hline $\begin{array}{l}\text { Changes } \\
\text { Any change }\end{array}$ & +1 & & & \\
\hline Loss of empathy & +1 & & & -1 \\
\hline Inappropriate affect & +1 & & & -1 \\
\hline Disinhibition & +1 & & & -1 \\
\hline Aggression & & -1 & & +1 \\
\hline \multicolumn{5}{|l|}{$\begin{array}{l}\text { Abnormal beliefs } \\
\text { and perceptions }\end{array}$} \\
\hline Suspicion & -1 & & & +1 \\
\hline \multicolumn{5}{|l|}{ Mood changes } \\
\hline $\begin{array}{l}\text { Distress in response to } \\
\text { handicaps }\end{array}$ & -1 & & & +1 \\
\hline $\begin{array}{l}\text { Anxiety in response to } \\
\text { handicaps }\end{array}$ & -1 & & & +1 \\
\hline Loss of confidence & -1 & & & +1 \\
\hline \multicolumn{5}{|l|}{ Physical symptoms } \\
\hline Myoclonus & & -1 & & +1 \\
\hline
\end{tabular}

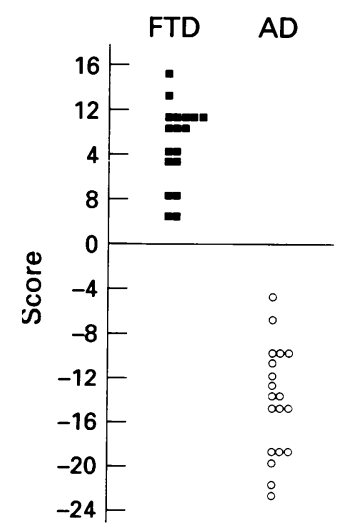

Scatter plot showing cumulated questionnaire scores for each patient with frontotemporal dementia (FTD) or Alzheimer's disease $(A D)$. initial phase of the questionnaire elicited positive responses in virtually all cases, and no differences emerged between frontotemporal dementia and Alzheimer's disease. This anticipated finding highlights the requirement of a questionnaire to direct questions to specific qualitative characteristics of the dementing disorder, rather than rely on questions relating to broad areas of dysfunction, and also to take account of the evolution of symptomatology over the disease course.

The questionnaire elicited the expected profiles of dysfunction: patients with frontotemporal dementia were distinguished from those with Alzheimer's disease by personality changes of disinhibition, lack of concern about the illness, loss of empathy with others, and social inappropriateness, and by the presence of mutism. Alzheimer's disease was differentiated from frontotemporal dementia by early disturbance of memory, topographical orientation, and perceptuospatial function, and by the presence of paraphasic, incoherent speech. Myoclonus and epilepsy were reported in Alzheimer's disease but not in frontotemporal dementia. This differential pattern mirrors closely the findings of previous prospective, longitudinal studies. ${ }^{1-39}{ }^{14}$ It is worth emphasising that such differences were elicited by the use of highly specific questions. A general question about personality change elicited positive responses with respect to both groups, but had different connotations for the two. Patients with Alzheimer's disease were perceived as "changed", because they were anxious, irritable, socially withdrawn, and lacking in confidence; in only frontotemporal dementia was there gross change in character and social conduct. In both groups, there was an almost invariable report of "loss of insight", yet a directed question regarding patients' emotional reaction to their illness showed a highly significant group difference: patients with frontotemporal dementia were typically reported as showing lack of concern, whereas patients with Alzheimer's disease showed distress.

It is important to note that although individual questions had discriminating value, for none was this absolute; that is, there were no questions reported positively with respect to $100 \%$ of one group and none of the other group. There are good reasons why this should be so. Features that may be regarded as characteristic of one patient group, such as myoclonus in Alzheimer's disease, are not invariably present. Secondly, there may be some overlap in symptomatology in the two conditions, particularly with disease progression. Indeed, that this is the case is supported by the greater differential value of questions when the period of symptom onset in the course of the disease is taken into account. Thirdly, even with questions designed to circumscribe a particular area of dysfunction a variety of underlying deficits might give rise to the same response to the questionnaire. For example, a dense amnesia in patients with Alzheimer's disease and distractibility and inattention in patients with frontotemporal 
dementia are both likely to give rise to a positive response to a question about "difficulty in new learning", or "loss of recent memory". Similarly, failure to orient clothing secondary to spatial disorder, and donning of inappropriate combinations of clothing secondary to loss of concern for personal appearance might both elicit a report of "dressing difficulties". There can be no single, critical question that has absolute sensitivity and specificity in identification of frontotemporal dementia and Alzheimer's disease, just as in clinical practice there is no single critical diagnostic test.

This fact highlights the need for examination not just of responses for individual questions, but of response profiles across the entire range of questions. It is the pattern of deficits, and evolution of symptomatology which allows, not just demonstration of group differences, but accurate classification of individual cases. Examination of profiles by one author, who played no part in the administration of the questionnaire elicited a highly accurate classification rate. This finding is important in that it establishes that questions do indeed tap what they are intended to tap, and information obtained retrospectively from informants accords with information that is routinely obtained from patients and their relatives in a clinical setting. It is clearly not sufficient, however, that such discrimination was possible. The examiner was familiar with the particular clinical population from whom data were derived. It would be important to ascertain whether similarly accurate classification could be obtained for a new sample of patients, with whom there had been no prior clinical contact. More importantly, classification based on profiles of responses requires clinical experience of both frontotemporal dementia and Alzheimer's disease, and a clear internalised model of their defining characteristics. A questionnaire reliant on such classification would be of limited universal use for family studies of dementia.

The scoring system is of value in that it provides a means of integrating information from responses to individual questions taking account of the evolution of symptoms, and is not dependent on the researcher's clinical experience. To avoid incorporating group difference data arising spuriously from multiple statistical comparisons, the scoring system used data only from questions that yielded a significant group difference at $\mathbf{P}<0.001$. All those group differences were entirely in accordance with clinical prediction. The scoring system effectively separated out the two groups, classification of individual cases being identical to that made by examination of response profiles by JS.

The question arises as to whether these clear cut dissociations are reproducible and might generalise to the general population of patients with frontotemporal dementia or Alzheimer's disease. Informants in this study had prior contact with hospital staff at the time of the patient's illness, raising the possibility that clinical information received at that time influenced their response pattern. It is unlikely, however, that such information significantly affected the results. Previous discussions would have focused on broad symptom profiles such as personality change and loss of insight in frontotemporal dementia and memory and visuospatial deficits in Alzheimer's disease, and it is at this broad level that prior tutoring of symptoms would be predicted to have an effect. Yet, at this general symptom level there were no significant group differences: all relatives reported deficits within each of the broad symptom areas. Differences emerged only at the subtle qualitative level: not whether memory problems were present, but whether a tendency to lose objects was noted; not whether insight was lost, but whether patients showed distress at difficulties. Moreover, many group differences related to time of onset of symptom, and not just its presence. It is inconceivable that relatives would have been schooled in such symptom intricacies, or would have retained such detailed verbal information several years after their relative's death. Indeed, one might expect rehearsed information to become generalised over time, leading to consolidation of broad symptom patterns. It is reasonable to assume, therefore, that informant responses reflect genuine memory of the patient's illness and not the product of information learnt from the clinician.

Interviews were undertaken a decade or more after symptom onset and some years after the patient's death, suggesting that detailed memories of a dementing illness are retained by relatives over many years. Although the accuracy of recall of an illness occurring 20 or 30 years before remains to be established, the present findings suggest optimism that accurate differentiating information would continue to be available.

The paucity of independent populations of patients with frontotemporal dementia established by pathology within the English speaking world restricts the feasibility of immediate replication of this study, although such replication is ultimately essential. There are, nevertheless, grounds for assuming that the patients employed in the study are representative of their diagnostic group. Unanimity of views between workers in Manchester and Lund, Sweden in establishing clinical criteria for the diagnosis of frontotemporal dementia ${ }^{7}$ suggested a common clinical experience of frontotemporal dementia in the two centres, despite the inherent differences in referral bias to a specialist neurological centre and a general department of psychiatry for elderly people. There was also accord with respect to the clinical differences between frontotemporal dementia and Alzheimer's disease. In any event, it might be argued that referral bias to a specialist centre would favour atypical patients who defy clinical diagnosis, which would have the effect of obscuring rather than clarifying the prototypical profiles on which diagnostic differentiation can be made.

Profiles of responses elicited by the questionnaire across a range of symptom areas permit the examination of associations in symptomatology in the two patient groups. It is 
of interest, for example, that aggression was reported more commonly in Alzheimer's disease than in frontotemporal dementia, despite the greater emphasis on personality and alteration of conduct in the frontotemporal dementia group. One might speculate that aggression may arise in Alzheimer's disease in association with feelings of frustration, distress, and disorientation, whereas the absence of aggression in frontotemporal dementia reflects their bland demeanour and lack of concern. Abnormal beliefs, delusions, and misidentification phenomena occurred almost exclusively in relation to patients with Alzheimer's disease, in whom memory and spatial symptomatology are prominent, raising the possibility that such neuropsychiatric symptoms may be secondary or at least strongly influenced by cognitive deficits.

The present study focused intentionally on the differentiation between frontotemporal dementia and Alzheimer's disease. Frontotemporal dementia continues to be underrecognised, patients typically being subsumed within the diagnostic rubric of presenile or senile dementia or assigned the label of dementia of Alzheimer type. Indeed, patients may fulfil NINCDS-ADRDA criteria for Alzheimer's disease. ${ }^{13}$ In family studies of frontotemporal dementia, putatively affected relatives are often diagnosed as having Alzheimer's disease. Accurate retrospective differentiation between the two conditions is therefore essential. Both frontotemporal dementia and Alzheimer's disease represent primary cortical cerebral degenerations, share a similar insidious onset and progressive course, and a relative absence of associated physical disability. Differentiation must therefore necessarily depend upon analysis of the pattern of dementia.

Dementing conditions other than primary cortical degenerations, such as vascular dementia, are typically distinguished from frontotemporal dementia by features other than the pattern of mental change: the historical course (acute $v$ chronic onset, progressive $v$ static mental disorder; stepwise $v$ insidious progression; rapid $v$ slow course), and physical symptomatology (for example, limb weakness; early loss of mobility). A family history questionnaire for use in frontotemporal dementia or Alzheimer's disease would need to include sections on history and physical changes to exclude a wider range of cerebral disorders. The purpose of the present questionnaire was not to provide a comprehensive diagnostic tool, but rather to enable accurate retrospective differentiation between two conditions for which the principal identifying characteristic lies in the pattern of dementia, and for which diagnostic confusion is commonly present.

The study illustrates that by the use of a structured interview, with questions which tap qualitative characteristics of the dementia, frontotemporal dementia can be differentiated with accuracy from Alzheimer's disease on the basis of retrospective information obtained from informants. An interviewer's previous clinical experience of the diagnostic groups is not a prerequisite, although a minimal degree of prior training ensures that the interviewer understands for each question the nature of the information being sought. Responses elicit dementia profiles that can be used to classify individual cases correctly, assisted by the use of a scoring system. Dementia questionnaires have, in the past, tended to rely on broad criteria, perhaps deriving from the commonly held belief that dementia is a global, undifferentiated impairment of mental function and that diagnostic distinctions cannot be made on neuropsychological grounds. ${ }^{23}$ Broad based questionnaires are likely to perpetuate that notion. Findings from the present study highlight the fact that dementias are associated with highly characteristic profiles of mental disorder. The questionnaire provides a means of differentiating retrospectively between frontotemporal dementia and Alzheimer's disease, and establishes the basis for a diagnostic instrument to be used in family history studies of dementia. There remains the need to replicate the findings in an independent patient sample and to extend the questionnaire to permit differentiation between these primary cortical dementias and other dementing conditions.

We thank Professor D Neary for providing clinical information about the patients, Dr D M A Mann for pathological information, and Mrs B Tomenson for advice on statistics. We also thank all the relatives who took part. This research was funded by the Wellcome Foundation.

1 Gustafson L. Frontal lobe degeneration of non-Alzheimer type. II. Clinical picture and differential diagnosis. type. II. Clinical picture and differential diagno

2 Neary D, Snowden JS, Northen B, Goulding P. Dementia of frontal lobe type. $\mathcal{F}$ Neurol Neurosurg Psychiatry 1988;51:353-61

3 Miller BL, Cummings $\mathrm{JL}$, Villanueva-Meyer J, Boone $\mathrm{K}$, et al. Frontal lobe degeneration: clinical, neuropsychological and SPECT characteristics. Neurology 1991;41:1374-82.

4 Neary D, Snowden JS, Mann DMA. The clinical pathoogical correlates of lobar atrophy. A review. Dementia 1993;4:154-9.

5 Brun A. Frontal lobe degeneration of non-Alzheimer type. I. Neuropathology. Archives of Gerontology and Geriatrics 1987;6:193-208.

6 Mann DMA, South PW, Snowden JS, Neary D. Dementia of frontal lobe type: neuropathology and immunohistochemistry. $f$ Neurol Neurosurg Psychiatry 1993;56: 605-14.

7 Brun A, Mann DMA, Englund B, Neary D, et al. Consensus on clinical and neuropathological criteria for fronto-temporal dementia. $\mathcal{F}$ Neurol Neurosurg Psychiatry 1994;57:416-8.

8 Gustafson L. Clinical picture of frontal lobe degeneration of non-Alzheimer type. Dementia 1993;4:143-8.

Gustafson L, Nilsson L. Differential diagnosis of presenile dementia on clinical grounds. Acta Psychiatrica Scandanavica 1982;65:194-209.

10 Orrell MJ, Sahakian BJ. Dementia of frontal lobe type. Psychol Med 1991;21:553-6.

11 American Psychiatric Association. Diagnostic and statistical manual of mental disorders. 3rd ed (revised). Washington DC: APA, 1987.

12 World Health Organization. International classification of diseases. 10th ed. ICD-10. Geneva: WHO, 1992

13 McKhann G, Drachmann D, Folstein M, Katzman R, Price D, Stadlan EM. Clinical diagnosis of Alzheimer's disease. Report of the NINCDS-ADRDA Working disease. Report of the NINCD
Group. Neurology 1984;34:939-44.

14 Neary D, Snowden JS, Bowen DM, Sims NR, Mann DMA, Benton JS, et al. Neuropsychological syndromes in presenile dementia due to cerebral atrophy. $\mathcal{F}$ Neurol Neurosurg Psychiatry 1986;49:163-74.

15 Neary D, Snowden JS, Mann DMA, Northen B, Goulding PJ, MacDermott N. Frontal lobe dementia and motor neurone disease. $\mathcal{f}$ Neurol Neurosurg Psychiatry 1990;53:23-32.

16 Sellwood W. Behavioural differences between dementia of the Alzheimer type and dementia of the frontal type [thesis]. Victoria University of Manchester, Manchester, 1989. 
17 Cummings JL, Miller B, Hill MA, Neshkes R. Neuropsychiatric aspects of multi-infarct dementia and dementia of the Alzheimer type Arch Neurol 1987;44:389-93.

18 Berrios GE. Non-cognitive symptoms and the diagnosis of dementia. Historical and clinical aspects. Br $\mathcal{F}$ Psychiatry 1989;154(suppl): 11-6.

19 Burns A, Jacoby R, Levy R. Psychiatric phenomena in Alzheimer's disease. I: disorders of thought content. $B r f$ Psychiatry 1990;157:72-6.

20 Burns A, Jacoby R, Levy R. Psychiatric phenomena in
Alzheimer's disease. II: disorders of perception. $B r \mathcal{F}$ Psychiatry 1990;157:76-81.

21 Burns A, Jacoby R, Levy R Psychiatric phenomena in Alzheimer's disease III: disorders of mood. $B r$ Psychiatry 1990;157:81-6.

22 Mann DMA, South PW. The topographical distribution of brain atrophy in frontal lobe dementia. Acta brain atrophy in frontal

23 Heston LL, White JA, Mastri AR. Pick's disease: clinical genetics and natural history. Arch Gen Psychiatry 1987; 44:409-11.

\section{Appendix}

\section{Informant-based Questionnaire}

A. Screen for Presence of Dementia and Identification of Time Course of Illness

1. At any stage during the illness did you notice any of the following changes in the subject?

$\begin{array}{lll} & \text { No } & \text { Yes } \\ \text { a) loss of memory } & 0 & 1 \\ \text { b) difficulty in language } & 0 & 1 \\ \text { c) loss of ability to read or write } & 0 & 1 \\ \text { d) getting lost/difficulty in cooking or dressing } & 0 & 1 \\ \text { e) impaired judgement } & 0 & 1 \\ \text { f alterations in personality } & 0 & 1 \\ \text { g) decline in level of functioning } & 0 & \end{array}$

2. Which was the first change that you noticed?

3. Was the onset sudden or gradual? $\mathrm{S} / \mathrm{G}$

4. Did any of these changes get worse a) steadily $\mathrm{Y} / \mathrm{N}$

5o the best of your recollection, when was the last time the subject was really well/old self?

6. When would you say you first noticed a change?

month/year-___ Age-_ _ _

[Now work out how long the subject was ill, clarify this with informant, and divide the total period into 3 roughly equal portions to be called early (E); middle (M) and late (L) phases.]

Explain to the informant that you will be asking him/her to try to remember whether symptoms were present, and if so, when they first developed i.e. E, $M$ or L phase. Try to identify key events to aid demarcation of phases.

\section{B. Identification of Pattern of Dementia}

\section{B1 Memory/Orientation}

General

At any stage during the illness did he/she have memory problems/become forgetful?

Recent memory/new learning

At any stage did he/she

a) have difficulty recalling recent events?

b) have difficulty in new learning?

(give examples)

c) regularly lose/misplace objects?

(give examples)

(give examples)

Remote memory

At any stage did he/she

a) have difficulty remembering events from distant past?

Wandering

b) reminisce about/live in the past?

At any stage did he/she wander (or need to be supervised to prevent wandering)?

If yes

a) usually followed same route?

Variability

b) usually got lost?

At any time did his/her memory vary according to task/motivation/will?

Orientation

At any stage did he/she regularly

a) mix up the time of day?

b) have difficulty knowing where he/she was?

\section{B2 Language}

General

At any time did he/she have difficulty communicating?

Characteristics of Language Disorder

Did he/she

a) use wrong words?

b) have favourite words which he/she kept repeating?

c) stutter?

d) copy/repeat words of others?

e) have difficulty putting names to objects/finding right word?

f) talk in incoherent/jumbled way which was difficult to understand?

g) lose train of thought and not finish sentences?

h) talk more than usual?

i) talk less than usual?

j) give only brief replies to questions?

k) initiate conversation less or not at all?

1) stop talking altogether?

Reaction to Disorder

Did he/she usually get anxious/distressed by communication difficulty?

Reading

Did he/she have difficulty reading/fail to understand what he/she read? 


\section{Calculation}

Did he/she have difficulty adding up/using money?

B3 Perceptuo-spatial skills and Praxis

General

At any time did he/she get lost/have difficulty dressing/using tools or utensils?

Topographical

At any time did he/she have difficulty finding the way

a) in unfamiliar places

b) in the neighbourhood

c) inside the home

Visuo-Perceptual

At any time did he/she have difficulty recognizing

a) familiar faces

Visuo-spatial/Praxic

At any time did he/she have difficulty

b) objects

a) getting dressed

b) using utensils/tools

c) locating objects placed in front of him/her

\section{B4 Personality and Behavioural Changes}

General

At any time did his/her personality change or did he/she behave out of character?

Apathylindifference

Did he/she show less interest in usual hobbies or leisure activities?

Lack of empathy

At any time did he/she become more selfish/show less consideration for others?

Impaired judgement

Did he/she make decisions which seemed ill-considered, impulsive or rash?

Impaired personal awareness

Did he/she let slip his/her standards of personal appearance and hygiene?

Lack of social awareness

Did he/she become ill-mannered/discourteous to others?

Inappropriate jocularity/fatuous affect

Did he/she laugh at unsuitable times/make jokes or comments in bad taste?

Disinhibition

Did he/she become less modest/become involved in embarrassing situations in public/act in a disinhibited manner?

Insight

Did he/she lose insight into the fact that he/she was ill?

Aggression

At any time did he/she become $\quad$ a) more aggressive/threatening

Inflexibility

b) less aggressive/more passive

At any time did he/she become more stubborn/set in his/her ways?

Stereotypies

Did he/she do the same thing repetitively/repeat the same behaviour over and over?

Obsessionality

Did he/she seem to have to repeat certain actions, and become distressed if prevented?

Hyperorality

At any time did he/she put inedible objects into his/her mouth?

Gluttony/sweet food preference

At any time did he/she

a) eat excessively

Distractibility

b) have an altered preference for sweet foods?

Did he/she become more distractible/less able to concentrate?

Restlessness

At any time did he/she become physically overactive/restless?

Hiding/hoarding

At any time did he/she a) hoard objects b) hide belongings

\section{B5 Abnormal Beliefs and Perceptions}

Suspiciousness

At any time did he/she become more suspicious/less trusting?

Persecutory ideation

At any time did he/she complain unjustifiably of being persecuted/spied on?

Ideas of Theft

At any time did he/she believe possessions had been stolen?

Misidentification

At any time did he/she a) misidentify familiar people

b) misidentify own mirror image

c) believe television events to be real (taking place in room)

d) believe other people to be living in the home

Abnormal Perceptions

At any time was he/she troubled by voices or visions, not experienced by others?

\section{B6 Mood}

Emotional reaction to disability

Would he/she react to his/her difficulties by

a) becoming distressed/upset?
b) becoming anxious?

c) losing confidence?

Lowering of mood

At any time would he/she seem more tearful or depressed?

Elevation of mood

At any time did he/she seem happier or more enthusiastic than is usual? 
Irritability

At any time did he/she become more irritable?

Emotional stability

Did he/she show rapid alterations in mood during the day?

Emotional blunting

Did he/she seem emotionally blunted/fail to react appropriately to good and bad news?

B7 Physical

Myoclonus

At any time did he/she develop twitching/jerky movements?

Dyskinesia

At any time did he/she develop other unusual movements?

Rigidity/tremor/bradykinesia

At any time did he/she become a) stiff b) tremulous c) slowed down?

Incontinence

At any time did he/she become incontinent?

Focal signs

At any time did he/she develop a) limb paralysis b) loss of vision c) slurred speech

Epilepsy

At any time did he/she develop fits/convulsions?

Gait abnormalities

At any time did he/she have difficulty walking? 